\title{
Unemployment and the Economics of
} Gradualist Policy Reform

\author{
by \\ Michael Gavin, Columbia University
}

June 1993

Discussion Paper Series No. 655 


\title{
Unemployment and the Economics of Gradualist Policy Reform
}

\author{
Michael Gavin \\ Department of Economics \\ Columbia University \\ First draft: January, 1993 \\ This draft: April 1993
}

\begin{abstract}
This paper investigates the efficiency of adjustment to economic reform programs when the cost of adjustment arises from the unemployment that can be generated as contracting sectors shrink faster than expanding sectors can grow. Under plausible assumptions on the adjustment process, the speed of adjustment to "shock therapy" reforms is shown to be excessively rapid, and the rate of unemployment to be excessively high during the transition to the new equilibrium. The authorities can improve the efficiency of the adjustment by removing the distortion gradually, rather than abruptly. Gradualism has beneficial income distributional, as well as efficiency properties, because it improves welfare of the unemployed, who are necessarily the least advantaged social group in this model.
\end{abstract}




\title{
Unemployment and the Economics of Gradualist Policy Reform
}

\author{
Michael Gavin ${ }^{1}$ \\ Department of Economics \\ Columbia University \\ First draft: January, 1993 \\ This draft: April, 1993
}

\section{Introduction}

Governments often pursue economic reform programs that have major implications for the structure of the economy. Notable examples include the industrial restructuring generated by the contraction of military expenditure now underway in the United States, the movement from highly protectionist import-substitution development strategies toward more liberal trade regimes that has recently taken place in many Latin America and African economies, and the even more notable series of reforms being undertaken by formerly-socialist economies in Eastern Europe and the former Soviet Union, China, and Africa. Though these examples clearly differ in many important ways, they are similar in two key respects. First, if the reforms are successful, the reforming economy will look very different after their completion than at it did at the outset of the reform program. And second, while there is often surprisingly little disagreement over the final objectives of the reform, there is bitter disagreement over the strategy to be followed during the transition period.

This disagreement is over several dimensions of the transition process, including the timing, sequencing, and speed of the reform program. In this paper I focus on the appropriate speed of economic reform - specifically, on the relative merits of "gradualist" versus "shock-therapy" approaches to reform. The point of departure is Mussa's (1982) influential work, which made the important point that the costliness of adjustment to major structural reforms does not necessarily imply that adjustment of policy should be gradual. He showed that, in a world with frictionless

\footnotetext{
${ }^{1}$ I gratefully acknowledge helpful discussions with Andrew Caplin, Vivek Dehejia, Jon Eaton, John Haltiwanger, Bruce Meyer, Joe Tracy, Mancur Olsen, and Stanislaw Wellisz. I am also grateful for the hospitality of the Vienna Institute for Advanced Studies, whose stimulating yet peaceful environment contributed materially to completion of this paper. Useful comments at seminar presentations at Columbia, Harvard and New York Universities, the World Bank, and Universität Mannheim are also acknowledged with gratitude.
} 
markets and rational expectations, and in which all costs of adjustment are internalized by the private sector, it is optimal for the government immediately to adjust the previously distorted policy instrument to its first-best level, while allowing the private economy to adjust gradually in response to the incentives generated by the reform.

This strand of the theoretical literature provides a powerful intellectual case for "shock-therapy", and demonstrates that the case for gradualism must be grounded in second-best arguments created by some departure from the frictionless economic structure considered in Mussa's contribution. Early attempts to introduce such "frictions" did not provide clear lessons on the relative merits of slow versus abrupt reform strategies. ${ }^{2}$ One reason for this may be that the various frictions introduced have been in some sense orthogonal to the process of structural adjustment itself, including for example distortionary labor or capital income taxation, temporarily sticky wages or prices, and departures from rational expectations.

More recently, several papers have sought to focus on ineffiencies inherent in the adjustment process itself. For example, Dixit and Rob (1992) show that, in the absence of perfect insurance markets, rapid private-sector adjustment reduces relative-price variability and therefore the amount of risk that must be borne by the private sector. Because individuals do not incorporate this external benefit of rapid adjustment in their decisionmaking, the speed of adjustment under laissez faire will be excessively slow. In Caplin and Leahy (1992) there is an information externality generated by the fact that all agents can learn something about the true state of the world when a single agent adjusts. Again, in equilibrium there is a suboptimal speed of adjustment to various shocks, the welfare consequences of which are aggravated by gradual policy changes.

While such risk and information externalities may play a role, in practice the most controversial and socially divisive aspect of economic reform is the unemployment with which economic adjustment to reform is often associated. It is essential, therefore, to evaluate alternative reform strategies within a framework that can articulate the link between the various proposals and unemployment. Here, the

\footnotetext{
${ }^{2}$ Mussa (1982), Neary (1982).
} 
literature on optimal commercial policy in the presence of unemployment ${ }^{3}$ provides some help. However, in that literature unemployment is assumed to result from some form of nominal or real wage rigidity. The implications of such rigidity are quite sensitive to the precise form that they take, and since the rigidities are posited not derived, papers based upon such wage rigidities provide limited insight into actual adjustment experience.

Moreover, this quasi-Keynesian view of unemployment misses important dimensions of the unemployment that threatens an economy contemplating a major restructuring like those underway in the former Soviet Union, or formerly-socialist African countries, where the key question is: what will happen to workers released as the state-owned or parastatal sector is shut down? Here the problem has little to do with real or nominal wage rigidities, and much to do with the fact that existing enterprises can be closed very quickly - in principle instantly - while creation of new enterprises into which factors of production might more productively be employed takes time, as entrepreneurs search for new activities in which to employ their talents, overcome unexpected obstacles along the way, and generally seek out ways of responding to the new economic environment. While this process is underway, workers and other factors of production released from the declining sector experience unemployment.

This view of transition unemployment differs from conventional Keynesian stories in at least two respects. First, such unemployment is a dynamic phenomenon, and it cannot instantaneously be eliminated by adjustments in monetary, fiscal, or industrial policy. More to the point, it probably shouldn't be: unemployment is a natural, even essential feature of the adjustment process, for it is the unemployed workers, entrepreneurs, and owners of capital resources that have the strongest incentive to find creative ways of adapting to the new economic climate.

This does not, however, imply that the unemployment generated in response to a major economic reform will be either efficient or equitable. This paper constructs a simple model of economic adjustment with unemployment and demonstrates that - under intuitively plausible assumptions on the nature of the adjustment process that have some empirical support - "shock-therapy" approaches

${ }^{3}$ See in particular Johnson (1965), Lapan (1976), Neary(1982), and Rodrik(1987). 
to reform can lead to an excessively rapid speed of adjustment, the result of which is an excessively high rate of unemployment during the transition to the new equilibrium. The model also indicates that gradualist reform strategies can effect a more efficient transition. Finally, though this argument for gradualism is grounded in efficiency considerations alone, it is a nice coincidence that gradualism has beneficial income distributional, as well as efficiency properties. This is because gradualism benefits the unemployed, who are necessarily the least advantaged social group in this model.

The paper is organized as follows. Section II describes the economic environment and discusses the response to an economic reform in a decentralized equilibrium. Section III describes the adjustment path that would be selected by a social planner. Section IV compares the adjustment trajectories, discusses the inefficiency of the decentralized equilibrium under "shock therapy", and explains how a gradualist approach to reform can alleviate the inefficiencies that would emerge, while at the same time improving income-distributional outcomes. Section V concludes. Throughout, the discussion focuses on the economic intuition for the results; readers who would like a closer look at the straightforward but tedious formal analysis of the model may consult an appendix to the paper, which is available from the author upon request.

\section{Adjustment in a Decentralized Equilibrium}

\section{A. The adjustment process}

In actuality the reforms that concern us can be quite complicated, but if there is to be any hope of conducting a dynamic welfare analysis some simplification will be required. We therefore consider a two-sector economy which is initially distorted by the existence of a production subsidy in one of the sectors; "reform" means elimination of this subsidy. This is a fairly realistic description of some reforms, such as a trade liberalization, though it is only a crude metaphor for others. In any event, the government is assumed to understand the welfare costs of the subsidy, and all parties are in agreement on the need eventually to remove it. The question is whether it should be removed gradually or abruptly. The reader will see that the transition problems identified here would emerge in the aftermath of many, potentially more complicated economic reforms, though one cannot of 
course rule out the possibility that more complicated reforms will introduce additional transitional problems not considered here. ${ }^{4}$

Upon initiation of the reform program it is assumed that the economy has settled into a long-run equilibrium, distorted by the production subsidy, in which a suboptimally large proportion of the economy's resources are located in the favored sector. A "shock therapy" reform removes the production subsidy instantly, and allows the private sector to adjust to the new incentives. A "gradualist" reform is modeled by assuming that the production subsidy, rather than being set to zero instantly, is eliminated gradually.

In this context, "adjustment" refers to the process of moving mobile factors of production from the contracting to the expanding sector, and the speed of adjustment is an issue because it is costly to move factors from one sector to another, and may be much more costly if it is done quickly. For brevity, we will refer to the mobile factor as "labor", though the label should be given a broad interpretation. In fact, reallocations of physical and human capital, as well as entreprenurial energies, may be at least as important as those of raw human labor, and may pose the more substantial costs of adjustment. Nevertheless, movement of labor and the associated unemployment of workers is a major cost of reform, and certainly represents the most politically sensitive issue in many reform episodes, so our terminological emphasis on the labor market is not completely misleading.

The costs of adjustment arise from the assumption that factors of production cannot move directly from one sector to another, but must abandon one sector before searching for employment opportunities in the other sector. The search for employment opportunities is assumed to be sector-specific, and unemployed workers must decide in which sector to look for production opportunities. ${ }^{5}$ The speed of adjustment will depend, first, upon the number of unemployed workers

\footnotetext{
${ }^{4}$ It may be worth noting that the potential transition problems identified here will also apply to cases in which the economy is adjusting to exogenous external disturbances, such as to changes in the terms of trade or world interest rates, so that the case for gradualism articulated here may also generate the presumption that policy should intervene to reduce the speed of adjustment to large external shocks.

${ }^{5}$ The assumption that factors cannot search for work in another sector while employed is common in the search literature, and is a tractable way of reflecting the relatively higher efficiency of such search by inactive factors of production. The assumption that workers can only search in one sector at a time is inessential; the model can also be interpreted as determining the fraction of each worker's time that is devoted to searching for
} 
available to search for employment opportunities in both the expanding and the contracting sectors, and second upon the proportion of the unemployed who search for work in the expanding vs. the contracting sector. Workers are therefore able to influence the adjustment process in two ways: first, by choosing to abandon the contracting sector they increase the number of workers searching for employment opportunities, and hasten the speed with which the expanding sector grows. And second, for any given level of unemployment, the fraction of the unemployed workforce who to look for work in each sector determines how fast one sector expands relative to the other. We will show that both decisions are inefficiently made in a decentralized equilibrium. Toward that end, we now turn to a more detailed description of the economic environment.

\section{B. Demand}

Consumers obtain utility from consumption of two goods, which are labeled $X$ and $Y$. Consumers have access to an integrated world commodity market, and we choose units so that the goods trade at a relative price of unity. In order to focus attention on potential transition problems, it will be convenient to impose a substantial degree of symmetry on the model, and the first such assumption is that the two goods enter consumer's utility function symmetrically. This implies that domestic consumption of the two goods will, in equilibrium, be equal. In order to focus attention on the goods- and labor-market phenonena that matter here, I assume that there is no international trade in assets, so that the current account is necessarily in balance at all times.

In order to avoid complications introduced by risk-aversity or imperfect intertemporal substitutability of consumption that are not a focus of this paper, the utility function is assumed to display constant returns to scale in the two goods, which implies both risk neutrality and perfect intertemporal substitutability of total consumption. An implication of this is that the equilibrium real interest rate must be equal to the pure rate of time preference, here denoted $\rho$, which is assumed to be constant. Workers will maximize utility by maximizing the present value of anticipated future income, discounted at this equilibrium interest rate. The choices available to workers are discussed below. sector in which they will find employment; without this their behavior is simply irrelevant. 


\section{Supply and factor returns}

Both goods are produced using labor and a fixed factor specific to each sector. To maintain symmetry, we assume that supply functions for the two goods are identical:
1a) $X=f\left(L_{x}\right)$
$f^{\prime}\left(L_{x}\right)>0, \quad f^{\prime \prime}\left(L_{x}\right)<0$
1b) $Y=f\left(L_{y}\right)$

where the (fixed) supply of the immobile factor is suppressed as an argument.

Workers will be employed up to the point at which the real wage equals the (after-subsidy) value marginal product of labor:
1c) $\quad w_{x}=f^{\prime}\left(L_{x}\right)$
1d) $\quad w_{y}=f^{\prime}\left(L_{y}\right)(1+s)$

where $s$ is the subsidy which represents the distortion that is, either gradually or abruptly, to be removed. This assumption on factor pricing is clearly unrealistic in many contexts, but it allows for explicit comparison with the existing literature discussed above.

Unemployed workers are assumed to earn a "wage" that we denote $\bar{w}$. This could be zero, or it could be positive, representing the value of leisure enjoyed or home-production generated by the unemployed. Alternatively, $\bar{w}$ could be negative if the job-search activities involve economic costs or if the unemployed tend to engage in socially costly behavior like rioting. What is important is the assumption that $\bar{w}$ is assumed to equal both the private and the social flow return to an unemployed worker's time; we discuss policies that may drive a wedge between the private and public values toward the end of the paper.

\section{Labor market dynamics}

The two key assumptions are that (i) workers must be unemployed to search for employment, and (ii) job-search is sector-specific. These assumptions are expressed in the following expression for the net flow of workers into the two production sectors:

2a) $\dot{L}_{x} \leq \Phi\left(U_{x}\right)-\delta L_{x}$

2b) $\quad \dot{L}_{y} \leq \Phi\left(U_{y}\right)-\delta L_{y}$

where $L_{x}$ and $U_{x}$ denote employment in the $X$ sector and the number of unemployed seeking work in the $X$ sector, respectively, with $L_{y}$ and $U_{y}$ defined analogously. In (2) the function $\Phi\left(U_{i}\right)$ gives the gross flow of workers from unemployment into employment in sector $i$. It will be assumed that this 
flow is strictly increasing in its argument, but that the function $\Phi\left(U_{i}\right)$ exhibits less than constant returns to scale. An implication of this assumption is that the average escape rate from unemployment, $\phi\left(U_{i}\right) \equiv \Phi\left(U_{i}\right) / U_{i}$, is a decreasing function of unemployment itself; that is, on average it takes longer to find a job when the unemployment rate is high. This important feature of the model is consistent with casual descriptions of the adjustment process, and has substantial empirical support. ${ }^{6}$

The net increase in employment is equal to the gross flow less an exogenous flow of workers from employment in each sector to unemployment, less a "normal" rate of job loss equal to $\delta L_{x}{ }^{7}$ Equation (2) is written as an inequality because, in addition to this "normal" job loss in each sector, workers may at any time voluntarily abandon a sector, become unemployed, and search for work in the other sector.

\section{E. Workers' choices}

Workers make two important choices. If currently unemployed, the worker must decide whether to search for employment in the $X$ sector or in the $Y$ sector. $^{8}$ If currently employed in one or the other sector, workers have to decide whether or not to quit their job and join the pool of unemployed, which allows them to search for employment in the other sector.

To understand workers' behavior we therefore need to determine the value of being employed in each sector, and the value of being unemployed searching for work in one or the other sector. These

${ }^{6}$ Using aggregate U.S. data, Blanchard and Diamond (1990) estimate that a demand shock large enough to raise the unemployment rate by 0.3 percent would lower the probability of escape from unemployment to employment from 0.24 percent to .236 . Evaluated at an unemployment rate of 6 percent, this estimate implies that the elasticity of the "matching function" is 0.66 and the elasticity of the average escape rate is approximately -0.34. Using data on individual workers' unemployment spells, Meyer (1990) finds that an increase in the state unemployment rate significantly reduces an individual's rate of escape from unemployment. The results in Burda (1992) are more fragile, depending as they do upon whether time-dummies are including in the regression equation or not. When they are, the estimates for Czechoslovakia also show evidence that average escape rates are a decreasing function of the rate of unemployment.

7 This "job destruction" is included to make the steady-state properties of the model both plausible and easier to discuss; its magnitude is unimportant. See Davis and Haltiwanger (1990) for evidence on the importance of gross job creation and destruction in the United States economy.

${ }^{8}$ It is assumed that it is always better to be employed in at least one sector than it is to be unemployed, and that - within a given sector - all jobs are alike. This means that unemployed workers will always try to find employment in one or the other sector, and will never reject a job offer. 
values are equal to the present value of anticipated future wage income, conditional upon the current labor-market state:

$$
V_{i}(t) \equiv E\left\{\int_{t}^{\infty} w(s) e^{-p(s-t)} d s \mid \text { labor market state at time } \mathrm{t}=i\right\}
$$

We begin by describing workers' decisions conditional upon these values, then turn to the slightly more complicated problem of determining the values.

The decision whether to abandon a sector is trivial: if the value of being unemployed exceeds the value of being employed, the worker should abandon the sector and look for work in the other sector, otherwise he should stay employed in his current job.

An unemployed workers' decision in which sector to search for work is only slightly more complex. Consider first the case in which at least some unemployed workers are searching for work in each sector. ${ }^{9}$ Unemployed workers can instantly and costlessly change the sector in which they're searching for work, so this situation can only be an equilibrium if the values of searching for work in the two sectors are equal to one another. This, in turn, implies that the expected gain from finding work in one sector must equal the expected gain in finding work in the other sector, or:

3) $\phi_{x}\left(U_{x}\right)\left(V_{x}-V_{u}\right)=\phi_{y}\left(U_{y}\right)\left(V_{y}-V_{u}\right)$

where $V_{x}$ denotes the utility value of being employed in sector $X, V_{y}$ denotes the value of being employed in sector $Y$, and $V_{u}$ denotes the value of being unemployed. The left side of this equation is the expected gain of searching for work in $X$ which is, in turn, equal to the gain in welfare achieved if an employment opportunity is found, $\left(V_{x}-V_{u}\right)$, times the flow probability that such a job will be found, $\phi\left(U_{x}\right)$.

This condition determines the equilibrim allocation of search activity, as illustrated in Figure 1. The horizontal axis of that figure measures the number of unemployed at some moment. We measure $U_{x}$ increasing from the left axis and $U_{y}$ increasing from the right. The left side of (3) is represented by the downward-sloping curve, and the right side by the upward-sloping curve. Equilibrium is obtained at the intersection of the two curves, and it is easy to see that the equilibrium number of

\footnotetext{
${ }^{9}$ This situation characterizes the steady-state equilibrium, because the gross flows of workers out of each sector requires gross flows into each sector, which in turn requires some search activity in each sector. A comer solution, in which all workers are searching for work in one sector or the other, is a logical possibility, but it complicates the discussion without generating any interesting economic insights. I therefore make assumptions which rule out such corners except at the instant a reform program is initiated. See the appendix for details.
} 


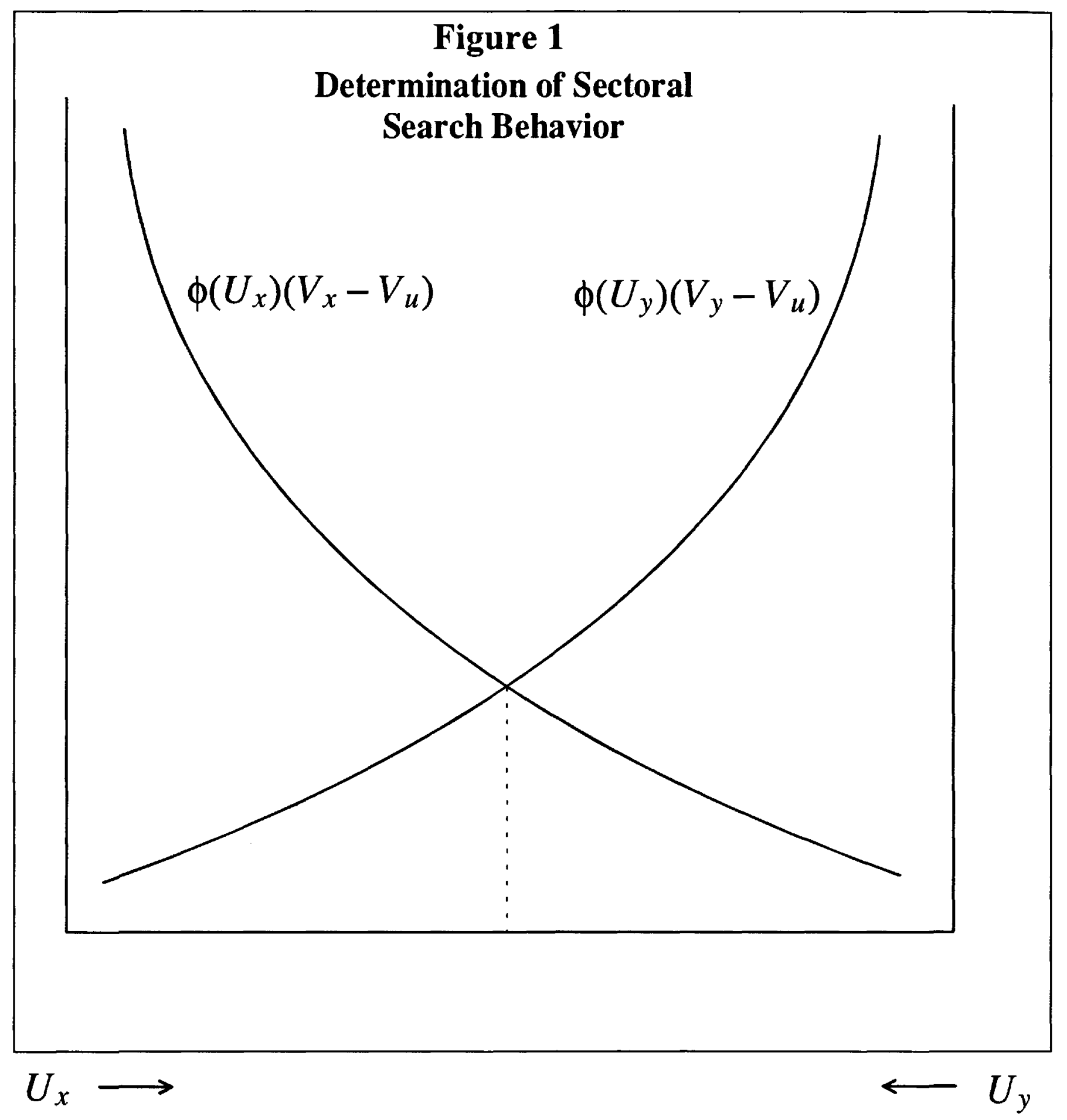


workers searching for work in sector $X$ is (i) increasing in the number of unemployed, $U$, (ii) increasing in the value of being employed in sector $X, V_{x}$, and (iii) decreasing in the value of being employed in sector $Y, V_{y}$.

A reduction in the value of being employed in sector $Y$ will, therefore, increase $U_{x}$ and therefore the gross flow of workers into $X$; as a result, the $X$ sector will start to expand. Meanwhile the $Y$ sector will begin to contract because the gross flow of workers into $Y$ falls short of the rate of "job destruction", $\delta L_{y}$. Eventually a new steady-state equilibrium would be reached in which employment is higher in sector $X$ and lower in sector $Y$. Of course this is not the end of the story, because the sectoral reallocations will have implications for the valuations $V_{x}, V_{y}$, and $V_{u}$, which have so far been held constant. We now endogenize these values.

It is straightforward to show that these values evolve as follows:

4a) $\quad \dot{V}_{x}=\rho V_{x}-\left\{w_{x}+\delta\left(V_{u}-V_{x}\right)\right\}$

4b) $\quad \dot{V}_{y}=\rho V_{y}-\left\{w_{y}+\delta\left(V_{u}-V_{y}\right)\right\}$

4c) $\quad \dot{V}_{u}=\rho V_{u}-\left\{\bar{w}+\phi_{x}\left(V_{x}-V_{u}\right)\right\}$

Equation (4a) defines the value of being employed in sector $X$ as the present value of anticipated flow returns from employment in that sector, discounted at the market interest rate $\rho$. This flow return, which is the term in curly brackets, includes two components. The first is the wage earned in sector $X, w_{x}$. The second is the contribution to expected utility generated by the possibility of a movement from employment to unemployment, which is the change in welfare resulting from such a transition $\left(V_{u}-V_{x}\right)$ multiplied by the flow probability of its occurrence, $\delta$. Equation (4b) defines the value of being employed in sector $Y$ analogously.

Equation (4c) defines the value of being unemployed searching for employment. The unemployed earn a "wage" of $\bar{w}$, and an additional flow return equal in expected value to the increment in utility generated by finding a job $\left(V_{x}-V_{u}\right)$ multiplied by the probability of such a transition occurring, $\phi_{x}$.

\section{F. Properties of the decentralized equilibrium}

Equations (2)-(4) plus the identity:

$$
N=L_{x}+L_{y}+U_{x}+U_{y}
$$

define seven equations in the unknowns $L_{x}, L_{y}, U_{x}, U_{y}, V_{x}, V_{y}, V_{u}$, of which five equations are dynamic. Solution of the model is made complicated but not interesting by the relatively high 
dimensionality of the system, and since it serves mainly to confirm intuition, I relegate the solution to the appendix and confine myself here to a discussion and explanation of the results.

An instantaneous elimination of the subsidy that had been granted to sector $Y$ leads to a reduction in sector- $Y$ wages, and therefore in the value of being employed in that sector, $V_{y}$. If the subsidy was small, this decline will be small as well, and $V_{y}$ will remain above the value of being unemployed, $V_{u}$. In this case, no factors will voluntarily abandon the $Y$ sector, but since fewer of the currently unemployed will search for work in that sector while more will search for work in the $X$ sector, employment in sector $Y$ will start to decline while employment in sector $X$ will increase. These changes in employment lead to gradual wage declines in the expanding sector, and wage increases in the contracting sector, until in the new steady-state equilibrium wages and the values of employment in the two sectors are brought into equality. During the transition to the new equilibrium there will be a bulge in the unemployment rate, because the concentration of search effort in the expanding sector generates a reduction in the aggregate escape-rate from unemployment. ${ }^{10}$

A second case arises when the reform program is large. Then the value of being employed in the contracting sector will threaten to drop below the value of being unemployed, and in response, some fraction of the factors employed in the contracting sector will abandon that sector upon initiation of the reform, thus leading to an immediate increase in the rate of unemployment. ${ }^{11}$ The adjustment is then qualitatively identical to that described above.

There is nothing particularly surprising about the adjustment pattern described here; except for the variations in unemployment along the adjustment path, it is qualitiatively similar to that described in Mussa (1982). But this qualitative characterization of the adjustment leaves open the question whether the equilibrium trajectory for unemployment is efficient. To address this question we turn now to the social planner's problem.

\section{Socially Optimal Adjustment}

${ }^{10}$ This is technically a second-order phenomenon, which will therefore be negligible for infinitesimally small reform programs.

${ }^{11}$ Voluntary "quits" or "bankruptcies" increase the value of employment in the expanding sector by raising the marginal product of labor and therefore the wage, and they lower the value of being unemployed because they lead to an increase in the average duration of an unemployment spell. The equilibrium number of "quits" or "bankruptcies" is the number required to prevent $V_{y}$ from falling below $V_{u}$. 


\section{A. The social planner's problem}

Consider the problem facing a benevolent social planner who wishes to maximize the present value of expected future domestic income. The planner cannot overcome the informational problems embodied in the search process described above, but can decide how many of the unemployed should be searching for work in each sector, and whether currently-employed in each sector should quit their jobs and enter the pool of unemployed. The planner's problem is:

5)

$$
\max _{\left\{L_{x}, L_{y}, U_{x}, U_{y}\right\}} \int_{0}^{\infty}\left(f\left(L_{x}\right)+f\left(L_{y}\right)+\bar{w}\left(U_{x}+U_{y}\right)\right) e^{-\rho t} d t
$$

subject to:

5a) $\quad N=L_{x}+L_{y}+U_{x}+U_{y}$

5b) $\quad \dot{L}_{x} \leq \Phi\left(U_{x}\right)-\delta L_{x}$

5c) $\quad \dot{L}_{y} \leq \Phi\left(U_{y}\right)-\delta L_{y}$

The Hamiltonian for this problem is:

$$
\begin{gathered}
H_{t}=\left[f\left(L_{x}\right)+f\left(L_{y}\right)+\bar{w}\left(U_{x}+U_{y}\right)\right]+\gamma_{x}\left(\Phi\left(U_{x}\right)-\delta L_{x}\right)+\gamma_{y}\left(\Phi\left(U_{y}\right)-\delta L_{y}\right) \\
+\lambda\left(N-L_{x}-L_{y}-U_{x}-U_{y}\right)
\end{gathered}
$$

First-order conditions for this problem are as follows:

6a) $\lambda=\bar{w}+\gamma_{x} \Phi^{\prime}\left(U_{x}\right)$

6b) $\lambda=\bar{w}+\gamma_{y} \Phi^{\prime}\left(U_{y}\right)$

6c) $\quad \dot{\gamma}_{x}=\rho \gamma_{x}-\left\{\left[f^{\prime}\left(L_{x}\right)-\delta \gamma_{x}\right]-\left[\bar{w}+\Phi^{\prime}\left(U_{x}\right) \gamma_{x}\right]\right\}$

6d) $\quad \dot{\gamma}_{y}=\rho \gamma_{y}-\left\{\left[f^{\prime}\left(L_{y}\right)-\delta \gamma_{y}\right]-\left[\bar{w}+\Phi^{\prime}\left(U_{y}\right) \gamma_{y}\right]\right\}$

The variable $\lambda$ represents the (flow) shadow value of an additional, unemployed worker, while the costate variables $\gamma_{x}$ and $\gamma_{y}$ represent the increment to social welfare that would be generated by a worker's transition from unemployment to employment in the $X$ and the $Y$ sectors, respectively. The costate variables $\gamma_{x}$ and $\gamma_{y}$ are the social counterparts to the private values $\left(V_{x}-V_{u}\right)$ and $\left(V_{y}-V_{u}\right)$. Equations (6a)-(6b) set the shadow value of an unemployed worker equal to the social marginal product, which comprises two terms. The first term, $\bar{w}$, represents the physical productivity of unemployed workers. The second, $\gamma_{i} \Phi^{\prime}\left(U_{i}\right)$ represents the social gain created by a transition to employment, multiplied by the increase in the number of such transitions generated by an increase in the number of unemployed. Combining (6a)-(6b), see that the social planner would allocate unemployed workers' search efforts to satisfy:

$$
\Phi^{\prime}\left(U_{x}\right) \gamma_{x}=\Phi^{\prime}\left(U_{y}\right) \gamma_{y}
$$


This rule is perfectly analogous to (3) and a similar intuition for it applies, except that the social planner cares about the social valuation $\gamma_{i}$ rather than the private valuation $\left(V_{i}-V_{u}\right)$, and uses the marginal escape-rate, $\Phi^{\prime}\left(U_{i}\right)$, not the average escape-rate, $\phi_{i}\left(U_{i}\right)$.

Equations (6c)-(6d) define the social value of a transition from unemployment to employment as the present-value, discounted at the market interest rate $\rho$, of expected future differences between the marginal productivity of employed and unemployed workers, where the (flow) social product of an employed worker includes the marginal physical productivity $f^{\prime}\left(L_{x}\right)$, minus the flow probability of job destruction, $\delta$, multiplied by the social cost of such a loss, $\gamma_{x}$. Similarly, the social product of an unemployed worker includes not only his physical productivity, $\bar{w}$, but also a term corresponding to the social value of the increase in expected transitions from unemployment to employment that results from the presence of one additional job-searcher: $\Phi^{\prime}\left(U_{x}\right) \gamma_{x}$. Again, it is the marginal rather than the average rate of escape from unemployment that matters to the social planner.

\section{B. Properties of the central planners' solution}

The solution to the central planner's problem is easily described because it is qualitatively identical to the decentralized equilibrium. When the initial distortion is small, the social planner will not eject workers from the declining sector, but will direct a larger fraction of the unemployed workers to search for productive opportunities in the expanding sector. This will effect a gradual movement of labor from the contracting to the expanding sector until a new long-run equilibrium is attained. If the initial distortion is large enough, the social planner will eject a fraction of the workforce employed in the contracting sector into the pool of unemployed, and the equilibrium then proceeds as just described.

\section{Comparison with the decentralized equilibrium}

For comparison with the social-planner's problem, define $\Gamma_{y} \equiv\left(V_{y}-V_{u}\right)$ as the private value of moving from unemployment to employment in sector $Y$. Subtracting (4c) from (4b), we see that this private counterpart to $\gamma_{y}$ satisfies:

$$
\dot{\Gamma}_{y}=\rho \Gamma_{y}-\left\{\left[(1+s) f^{f}\left(L_{y}\right)-\delta \Gamma_{y}\right]-\left[\bar{w}+\phi\left(U_{y}\right) \Gamma_{y}\right]\right\}
$$

This differs from (6d) in two ways. First, the private valuation incorporates the market wage $w_{y}=(1+s) f^{\prime}\left(L_{y}\right)$, which differs from the marginal product of labor if the subsidy is nonzero; this is why we call the subsidy a distortion. Second, the private valuation uses the average escape rate from unemployment, $\phi\left(U_{y}\right)$ rather than the marginal escape rate $\Phi^{\prime}\left(U_{y}\right)$. Why this is so should be obvious: the individual cares only about his own probability of escaping unemployment, which is 
equal to the average probability, while the social planner thinks about the impact of changes in the unemployment rate upon the aggregate flow of workers into or out of employment, which depends upon the marginal escape rate.

Under the assumption of decreasing returns to scale in $\Phi\left(U_{i}\right)$ the average escape rate will be larger than the marginal escape rate. This means that individuals' evaluation of the flow return to unemployment, $\left(\bar{w}+\phi\left(U_{y}\right) \Gamma_{y}\right)$ will be higher than the social planner's evaluation, $\left(\bar{w}+\Phi^{\prime}\left(U_{y}\right) \gamma_{y}\right)$. Workers will therefore underestimate the gain from employment: $\Gamma_{y}<\gamma_{y}$. In short, workers will not fear unemployment as much as a social planner would have them do. The reason for this is that when deciding to become unemployed, workers lower the average rate of escape from unemployment not only for themselves, but also for other currently unemployed workers. Because they do not bear the entire cost of decisions to become unemployed - or decisions to act in ways that prolong the average duration of their unemployment spell, workers do not fear unemployment enough

\section{The Efficiency of Adjustment under "Shock Therapy" and Gradualism}

\section{A. Inefficiency of "shock therapy"}

Under the various symmetry assumptions made above, this distortion does not affect the efficiency of the undistorted steady-state to which the economy eventually converges. It does, however, create inefficiencies in the dynamics of adjustment to that steady state. Specifically, it is easily shown that in the decentralized equilibrium the speed of adjustment will be too rapid. This is for two reasons. First, a suboptimally high fraction of the unemployed factors will be searching for work in the expanding sector. Second, when the reform is large enough to induce voluntary "quits" or "bankruptcies" in the contracting sector, too many workers will abandon the declining sector to search of employment in the expanding sector. The cost of this excessively rapid speed of adjustment is a higher rate of unemployment during the transition to the new steady state.

The intuition for the second source of inefficiency, the excessively high rate of "bankruptcy" is immediate, once the essential distortion is understood. Because of the negative externality described above, workers do not fear unemployment enough; they are as a result too willing to abandon a productive sector and become unemployed, in hopes of finding employment in the expanding sector. 
The first source of inefficiency is only slightly harder to grasp. Consider equation (3), which summarizes the tradeoffs as perceived by an unemployed worker trying to decide in which sector to search for work. The value of finding employment in the expanding sector will of course be higher than the value of finding a job in the contracting sector: $\left(V_{x}-V_{u}\right)>\left(V_{y}-V_{u}\right)$. A large number of the unemployed will therefore search for work in the expanding sector, which lowers the escape-rate from unemployment into that sector: $\phi_{x}<\phi_{y}$. In equilibrium, unemployed workers trade off the relatively large benefits of finding job in the expanding sector against the longer duration of unemployment that they can expect to experience if searching in the expanding rather than the contracting sector. Because workers do not fear unemployment enough, they will pay insufficient attention to the unemployment consequences of searching for work in the expanding sector, and will be suboptimally willing to experience a longer duration of unemployment in hopes of finding work in the high-value sector. The result is an unemployment rate during the transition in excess of that which would be chosen by a social planner.

\section{B. Gradualism: Efficiency and income distribution}

A number of interventions might be contemplated to address the inefficiency identified above. One such intervention is implementation of a gradual, rather than an abrupt removal of the distorting subsidy. Maintainence of the production subsidy raises the wage received by workers in the declining sector relative to what they would earn after an abrupt reform. This causes the private value of employment in the declining sector to be higher than it would otherwise be, relative both to employment in the expanding sector, and to the value of unemployment. This reduces the incentive for unemployed inefficiently to concentrate their job-search efforts in the expanding sector, and it also reduces the incentive for the excessively rapid abandonment of the declining sector. Thus, a gradual implementation of the reform strategy offsets the tendencies toward excessively rapid adjustment and excessively high transitional unemployment that emerge under "shock therapy".

Gradualism is admittedly an indirect means of tackling the inefficiency identified here, which results from the fact that individuals do not bear the full social cost of their unemployment. An alternative, arguably more direct intervention would be to tax the unemployed. However, such a policy has income-distributional consequences that most would consider undesirable; it lowers the welfare of 
the unemployed who are, in this model, necessarily the most disadvantaged of the three social groups that can be identified. A gradual reform, on the other hand, raises welfare of the unemployed, mainly because it lowers the number of unemployed, thereby increasing the probability of escape from unemployment to employment during the period of transition. Though distributional considerations were, for the sake of tractability, not injected explicitly into the social planner's problem, it is reassuring that gradualism possesses attractive distributional, as well as the efficiency properies in this model.

\section{Conclusion}

This paper argued that, under conditions that appear to characterize the actual process of factormarket adjustment, the "shock-therapy" approach to economic reform may generate an excessive private-sector response to the changed incentives, leading to excessively rapid adjustment and a resultant, excessively high rate of unemployment during the transition. The suboptimal private-sector response results from the congestion externality implicit in the hypothesis that the gross flow out of unemployment is less-than-proportionately increasing in the number of unemployed, for which there is substantial though certainly not definitive evidence. The implied externality is closely akin to that exposited in Gordon's classic analysis of fisheries; individuals base their behavior on average returns when marginal returns are relevant. Put differently, when one individual decides to become unemployed - or to act in ways that prolong the expected duration of his unemployment spell - he imposes a cost on those already unemployed by reducing the probability that they will find employment. It is this difference between the private and the social cost of unemployment that induces the private sector to respond suboptimally to "shock-therapy" reforms.

Gradualism can ameliorate the efficiency costs of this externality. It is not the only policy that could do so; for example, imposition of a tax on the unemployed would provide an even more direct way of bringing the private and social costs of unemployment into conformity with one another. But whereas the distributional consequences of such a scheme make it politically unthinkable, the distributional consequences of gradualism are favorable; in particular, the unemployed gain from a gradualist approach to reform, whereas they would certainly lose from an unemployment tax. 
Despite its low likelihood of enactment, it is useful to think about an unemployment tax because its reverse - unemployment compensation - is a feature of many economies undergoing major structural reforms. Just as an unemployment tax would ameliorate the transition costs of a "shock-therapy" reform, such unemployment compensation will aggravate them, by further widening the gap between the private and public costs of unemployment. Gradualism and unemployment compensation are in an important sense both substitute and complementary policies; on the on hand, the distributional consequences of gradualism make unemployment compensation less necessary, while on the other hand the high transition costs that would be generated by unemployment compensation under shock therapy can, to some extent at least, be ameliorated with a gradualist, rather than an abrupt economic reform.

The analysis upon which these conclusions are based is of course very stylized, and it could be extended in at least four directions. First, since so much hinges upon the characteristics of the function $\Phi\left(U_{i}\right)$, it would be useful to have a better understanding how it is determined. Most recent macroeconomic analysis has taken this function as a primitive feature of the economic environment, but of course it is not, and there is always the danger that policy interventions could shift the function in ways not captured by the above analysis. Second, there is a need for empirical work on the magnitude of the inefficiency identified here. One advantage of the theoretical framework adopted above is that it has recently received substantial empirical attention, and it would not be hard to use this empirical work to explore the magnitude of the economic costs of "shock therapy". Third, the model of adjustment could be placed in a more detailed and realistic economic environment. For example, the assumption of marginal-product factor-pricing has been replaced in Aghion and Blanchard (1993) with the assumption that workers in the expanding (private) sector are paid efficiency wages, while workers in the contracting (state) sector are paid the average product of labor. A cost of such elaboration is that the analysis will become economy- and even episode-specific, but it will probably be necessary for serious policy analysis. Finally, political-economy considerations that have been suppressed in this paper could be introduced explicitly. ${ }^{12}$ 
It may well be that further and empirical theoretical work overturns the case for gradualism outlined in this paper, perhaps because political rather than purely economic considerations are decisive. The unemployment costs of "shock therapy" identified in this paper should nevertheless be borne in mind, and alternative means sought to ameliorate the inefficiencies and inequities generated by the excessive unemployment that is likely to emerge in a "shock therapy" program.

${ }^{12}$ Dehejia (1993) analyzes the politics of gradualism in a similar model, emphasizing constraints imposed on policymakers by the need to maintain support of workers in the contracting as well as the expanding sector of the economy. 


\author{
Michael Gavin \\ Columbia University \\ Revised: April, 1993
}

\title{
I. Socially Optimal Adjustment
}

\section{A. The planner's problem:}

First-order conditions for the social planner's problem are:

A1.a) $\dot{\gamma}_{x}=\left(\rho+\delta+\Phi^{\prime}\left(U_{x}\right)\right) \gamma_{x}-\left(f^{\prime}\left(L_{x}\right)-\bar{w}\right)$

A1.b) $\quad \dot{\gamma}_{y}=\left(\rho+\delta+\Phi^{\prime}\left(U_{y}\right)\right) \gamma_{y}-\left(f^{\prime}\left(L_{y}\right)-\bar{w}\right)$

A1.c) $d L_{x}=\left(\Phi\left(U_{s}\right)-\delta L_{x}\right) d t-q_{x}$

A1.d) $d L_{y}=\left(\Phi\left(U_{y}\right)-\delta L_{y}\right) d t-q_{y}$

A1.e) $\quad \gamma_{x} \Phi^{\prime}\left(U_{x}\right)=\gamma_{y} \Phi^{\prime}\left(U_{y}\right)$

A1.f) $\quad N=L_{x}+L_{y}+U_{x}+U_{y}$

where $q_{x}$ and $q_{y}$ refer to the number of workers who voluntarily quit their job at some moment in time. Though not an essential assumption, it will simplify the exposition to assume the $\Phi\left(U_{i}\right)$ is a power function:

$$
\Phi\left(U_{i}\right)=\bar{\phi} U_{i}^{\sigma} \quad i=x, y
$$

The only important feature of (A2) is that individuals' instantaneous probability of finding work becomes infinitely large as the number of unemployed seeking work approaches zero, which rules out comer solutions in which all workers look for work in the expanding sector, except when $\gamma_{y}=0$. As we show below, this will occur (if ever) only at the moment a reform program initiated, which means that we need not worry about the possibility of such comers after the program is underway.

In the equilibrium described below, $q_{x}$ will always be equal to zero, and $q_{y}$ will be equal to zero except (possibly) at the instant the reform program begins. After that moment, (A1.c-A1.d) can be written:

$$
\text { A1.c') } \quad \dot{L}_{x}=\Phi\left(U_{x}\right)-\delta L_{x}
$$$$
\text { A1.d') } \quad \dot{L}_{y}=\Phi\left(U_{y}\right)-\delta L_{y}
$$

with $q_{y}$ serving to determine the intitial condition on $L_{y}$ and the rate of unemployment. Using equations (A1.e), and (A2) we can solve for the equilibrium search patterns:

$$
\begin{aligned}
& \text { A3) } \quad \frac{U_{y}}{U_{x}}=\left\{\frac{\gamma_{y}}{\gamma_{x}}\right\}^{1 / 1-\sigma)}, \text { or: } \\
& \text { A3') } \quad U_{x}=\left\{\frac{\gamma_{x}^{1 /(1-\sigma)}}{\gamma_{x}^{1 /(1-\sigma)}+\gamma_{y}^{1 /(1-\sigma)}}\right\} U,
\end{aligned}
$$

where $U \equiv U_{x}+U_{y}$ is the total number of unemployed.

It is useful to express the dynamic system described so far in terms of the following key variables:

- $U=U_{x}+U_{y}:$ Total unemployment.

- $M \equiv L_{x}-L_{y}$ : The misallocation of labor (in an undistorted equilibrium $L_{x}=L_{y}$.)

- $\Delta_{s} \equiv \gamma_{x}-\gamma_{y}$ : The value of moving a worker from sector $Y$ to sector $X$.

- $\gamma_{y}$ : The value of moving a worker from unemployment to employment in $Y$. 
The evolution of total unemployment is easily computed from (A1.c'), (A1.d') and (A3'):

A4.a)

$$
\begin{aligned}
\dot{U} & =\delta(N-U)-\Phi\left(U_{x}\right)-\Phi\left(U_{y}\right) \\
& =\delta N-\delta U-\bar{\phi} U^{\sigma}\left\{\frac{\left(1+\Delta_{s} / \gamma_{y}\right)^{\sigma / 1-\sigma}+1}{\left[\left(1+\Delta_{s} / \gamma_{y}\right)^{\sigma / 1-\sigma}+1\right]^{\sigma}}\right\}
\end{aligned}
$$

Using the same equations, we obtain:

$$
\dot{M}=\bar{\phi} U^{\sigma}\left\{\frac{\left(1+\Delta_{s} / \gamma_{y}\right)^{\sigma / 1-\sigma}-1}{\left[\left(1+\Delta_{s} / \gamma_{y}\right)^{1 / 1-\sigma}+1\right]^{\sigma}}\right\}-\delta M
$$

As should be expected, when labor is more valuable in the $X$ than in the $Y$ sector $(\Delta>0)$ the social planner ensures that labor is reallocated toward that sector, so that $M$ tends to increase.

Subtracting (A1.b) from (A1.a) and imposing (A1.e) we obtain:

A4.c) $\quad \dot{\Delta}_{s}=(\rho+\delta) \Delta_{s}-\left(f^{\prime}\left(L_{x}\right)-f^{\prime}\left(L_{y}\right)\right)$

Finally, for convenience we repeat equation (A1.b):

A4.d) $\left.\quad \dot{\gamma}_{y}=\left(\rho+\delta+\Phi^{\prime}\left(U_{y}\right)\right) \gamma_{y}-\left(f^{\prime}\left(L_{y}\right)-\bar{w}\right)\right)$

Noting that $L_{x}=(N-U+M) / 2$ and $L_{y}=(N-U-M) / 2$, (A4) defines for dynamic equations in the four endogenous variables $\left(U, M, \Delta_{s}, \gamma_{y}\right)$.

\section{B. Initial conditions}

Before the reform program is announced, $M<0$ because sector $Y$ has been subsidized, inducing too much labor to flow into that sector. Let $\widetilde{M}$ denote this pre-existing misallocation of the workforce: its size clearly depends upon the magnitude of the subsidy that is being removed. As part of the reform, the social planner will eject $q_{y} \geq 0$ workers from sector $Y$; we solve for $q_{y}$ below. The initial condition on $M$ is thus:

A5) $\quad M(0)=\tilde{M}+q_{y}$

where "time zero" refers to the moment just after the social planner begins the reform program. Unemployment will in the steady state be some number $\bar{U}$, which we characterize below. At time zero, this steady-state unemployment will be augmented by those workers who are ejected from the contracting sector, $Y$ :

A6)

$$
U(0)=\bar{U}+q_{y}
$$

\section{Properties of the steady state}

By inspection of (A1), we see that the social planner ensures that the economy will converge to a steady state in which:

- $\bar{\Delta}_{s}=0$, so that workers are equally valuable in each sector,

- $\bar{M}=0$, to that the labor-force misallocation is zero;

- the unemployment rate satisfies: $\delta(N-\bar{U})=2 \Phi(\bar{U} / 2)$, and

- $\bar{\gamma}_{y}=\frac{\left\{f^{\prime}((N-\bar{U}) / 2)-\bar{w}\right\}}{\left\{\rho+\delta+\Phi^{\prime}(\bar{U} / 2)\right\}}$

\section{Solution of the planner's problem}

I have not found it possible to solve the above non-linear system of equations (A4), so in the following discussion I follow (for example) Judd (1987) and base the analysis upon a linearized version of the system, where the linearization is around the steady-state to which the social planner drives the economy. This linearization neglects potentially interesting second-order effects, which I will discuss where appropriate. It may be useful in future to analyze the non-linear system using numerical simulation analysis. 
This linearization is:

A7.a) $\dot{U}(t)=-k_{1} \hat{U}(t)$

A7.b) $\quad \dot{\Delta}(t)=(\rho+\delta) \hat{\Delta}(t)+\alpha \hat{M}(t)$

A7.c) $\quad \dot{M}(t)=k_{2} \hat{\Delta}(t)-\delta \dot{M}(t)$

A7.d) $\quad \dot{\gamma}_{y}(t)=-k_{3} \hat{U}(t)+k_{4} \hat{\Delta}(t)-(\alpha / 2) \hat{M}(t)+k_{5} \hat{\gamma}_{y}(t)$

where variables with carets denote linear deviations from the steady state just described, and:

$$
\begin{aligned}
& \alpha \equiv f^{\prime \prime}\left(\bar{L}_{y}\right) \\
& \beta \equiv \Phi^{\prime \prime}(\bar{U} / 2)=\sigma(1-\sigma) \bar{\phi}(\bar{U} / 2)^{\sigma-2} \\
& k_{1}=\delta(1+\sigma(\bar{L} / \bar{U}))>0 \\
& k_{2} \equiv \frac{\Phi(\bar{U} / 2) \sigma}{(1-\sigma) \bar{\gamma}_{y}}>0 \\
& k_{3} \equiv\left(\beta \bar{\gamma}_{y}+\alpha\right) / 2>0 \\
& k_{4} \equiv \frac{\beta \bar{U}}{4(1-\sigma)}>0 \\
& k_{5} \equiv\left(\rho+\delta+\Phi^{\prime}(\bar{U} / 2)\right)>0
\end{aligned}
$$

The four eigenvalues of the system defined by (A7) are:

$$
\begin{aligned}
& -\lambda_{1}=-k_{1}<0 \\
& \lambda_{2}=1 / 2\left(\rho+\sqrt{\rho^{2}+4\left(\delta(\rho+\delta)+\alpha k_{2}\right)}\right)>\rho \\
& -\lambda_{3}=1 / 2\left(\rho-\sqrt{\rho^{2}+4\left(\delta(\rho+\delta)+\alpha k_{2}\right)}\right)<0 \\
& \lambda_{4}=k_{5}>\rho
\end{aligned}
$$

We have two initial conditions on $U$ and $M$, as discussed above. We have in addition two transversality conditions on $\Delta$ and $\gamma_{y}$ (equivalently on $\gamma_{x}$ and $\gamma_{y}$ ). With two negative eigenvalues and two eigenvalues larger than the rate of discount, $\rho$, these conditions define the unique optimal trajectory.

Imposing the initial condition (A6), the path for unemployment is:

$$
\text { A8.a) } \hat{U}(t)=q_{y} e^{-\lambda_{1} t}
$$

Equations (A7.b) and (A7.c) are then solved as a system, imposing a transversality condition on $\Delta$ and the initial condition on $M$ given by (A5). The result is:

$$
\hat{M}(t)=\left(\tilde{M}+q_{y}\right) e^{-\lambda_{3} t}
$$

A8.c)

$$
\hat{\Delta}(t)=\left(\tilde{M}+q_{y}\right)\left(\frac{-\alpha}{\rho+\delta+\lambda_{3}}\right) e^{-\lambda_{3} t}
$$

Finally, (A7.d) can be solved forward for $\hat{\gamma}(t)$, imposing the suitable transversality condition. We're primarily interested in $\hat{\gamma}(0)$ which is:

$$
\hat{\gamma}(0)=\int_{0}^{\infty}\left(k_{3} \hat{U}(t)-k_{4} \hat{\Delta}(t)+(\alpha / 2) \hat{M}(t)\right) e^{-\lambda_{4} t} d t
$$

Substituting for $\hat{U}(t), \hat{\Delta}(t)$ and $\hat{M}(t)$ and carrying out the indicated integration, we obtain: 


$$
\hat{\gamma}_{y}(0)=\frac{k_{3} q_{y}}{\lambda_{1}+\lambda_{4}}+\frac{\alpha\left(\frac{k_{4}}{\rho+\delta+\lambda_{3}}+\frac{1}{2}\right)\left(\tilde{M}+q_{y}\right)}{\lambda_{3}+\lambda_{4}}
$$

The second term can be simplified, to yield for the level of $\gamma_{y}$ :

$$
\gamma_{y}(0)=\bar{\gamma}_{y}+\frac{k_{3} q_{y}}{\lambda_{1}+\lambda_{4}}+\frac{(\alpha / 2)\left(\tilde{M}+q_{y}\right)}{\rho+\delta+\lambda_{3}}
$$

This puts us in a position to solve for $q_{y}$. Suppose first that $\widetilde{M}$ is not a very big (negative) number: that is, that the initial distortion is not too large. In particular, suppose that:

A10.a) $\tilde{M}>-\frac{\left(\rho+\delta+\lambda_{3}\right) \bar{\gamma}_{y}}{(\alpha / 2)}$

In this case $\gamma_{y}(0)$ is positive (and furthermore $\gamma_{y}(t)$ rises throughout the adjustment period). Since the value of a worker employed in the declining sector $Y$ is, in such an equilibrium, always larger than the value of an unemployed worker, it will never be optimal to eject workers from the declining sector, which is instead optimally shrunk through attrition. Thus, under (A10.a), the social planner will set $q_{y}=0$.

If, however, the initial distortion is very large, so that:

A10.b) $\quad \widetilde{M}<-\frac{\left(\rho+\delta+\lambda_{3}\right) \bar{\gamma}_{y}}{(\alpha / 2)}$

then $\gamma_{y}(0)$ would be negative if no workers were ejected from the declining sector at the beginning of the reform program. This would induce the social planner to eject workers from the declining sector, where they are socially less valuable than unemployed workers who are able to look for work in the expanding sector. These ejections will take place until $q_{y}(0)$ is equal to zero. Referring to (A9), we see that the equilibrium number of "quits" or "bankruptcies" is:

$$
q_{y}=-\left\{\bar{\gamma}_{y}+\frac{(\alpha / 2) \tilde{M}}{\rho+\delta+\lambda_{3}}\right\}\left\{\frac{k_{3}}{\lambda_{1}+\lambda_{4}}+\frac{(\alpha / 2)}{\rho+\delta+\lambda_{3}}\right\}^{-1}
$$

Now that we have solved for $q_{y}$ the solution to the planner's problem is complete. It can be characterized as follows:

- For small reform programs, specifically, when (A10.a) holds, the social planner will not eject workers from the declining sector, but will instead allow the sector to shrink through attrition. To a first order of approximation, the unemployment rate is unchanged throughout the adjustment process. ${ }^{1} M$ and $\Delta_{s}$ converge to the new steady state monotonically. The speed of adjustment is given by the stable eigenvalue $\lambda_{3}$, defined above.

- For large reform programs, when (A10.b) holds, the social planner will begin the reform program with a discrete ejection of workers from the declining sector. This raises the unemployment rate, which then declines monotonically toward the steady-state value. The speed with which the unemployment rate declines is given by the stable eigenvalue $\lambda_{1}$, defined above. Again, $M$ and $\Delta_{s}$ converge to the new steady state monotonically, with the same speed of adjustment as in a small reform program.

\section{Adjustment to Reform in a Decentralized Equilibrium}

\section{A. Conditions for decentralized equilibrium}

We express the competitive equilibrium in terms of five variables:

\footnotetext{
${ }^{1}$ This is an artificact of the linearization that we have been forced to do to obtain a solution. The concentration of search activity in the expanding sector will tend to reduct the aggregate escape rate from unemployment, and there would therefore be a gradual increase then decrease in the unemployment rate during the transition, but this is a second-order phenomenon.
} 
- $U \equiv U_{x}+U_{y}$ - the unemployment rate, as before;

- $M \equiv L_{x}-L_{y}$ - the labor force misallocation, as before;

- $\Delta \equiv\left(V_{x}-V_{y}\right)$ - the private value of moving from the declining to the expanding sector, analogous to $\Delta_{s}$ above;

- $\quad \Gamma_{y} \equiv\left(V_{y}-V_{u}\right)$ - the private value of moving from unemployment to employment in the contracting sector, analogous to $\gamma_{y}$ above.

- $\quad V_{u}$ - the private value of being unemployed.

The equations that define the decentralized equilibrium are:

A11.a)

$$
\dot{U}=\delta N-\delta U-\bar{\phi} U^{\sigma}\left\{\frac{\left(1+\Delta_{s} / \Gamma_{y}\right)^{\sigma / 1-\sigma}+1}{\left[\left(1+\Delta_{s} / \Gamma_{y}\right)^{\sigma / 1-\sigma}+1\right]^{\sigma}}\right\}
$$

A11.b)

$$
\dot{M}=\bar{\phi} U^{\sigma}\left\{\frac{\left(1+\Delta_{s} / \Gamma_{y}\right)^{\sigma / l-\sigma}-1}{\left[\left(1+\Delta_{s} / \Gamma_{y}\right)^{1 / 1-\sigma}+1\right]^{\sigma}}\right\}-\delta M
$$

A11.c) $\dot{\Delta}=(\rho+\delta) \Delta-\left(f^{\prime}\left(L_{x}\right)-(1+s) f^{\prime}\left(L_{y}\right)\right)$

A11.d) $\left.\quad \dot{\Gamma}_{y}=\left(\rho+\delta+\phi\left(U_{y}\right)\right) \Gamma_{y}-\left((1+s) f^{\prime}\left(L_{y}\right)-\bar{w}\right)\right)$

A11.e) $\quad \dot{V}_{u}=\rho V_{u}-\left(\bar{w}+\phi\left(U_{y}\right) \Gamma_{y}\right)$

where $s$ is the subsidy that applies at a given point in time. (For "shock therapy" reforms this is equal to zero; for "gradualist" reforms this shrinks to zero gradually.)

\section{$B$. Characteristics of the undistorted steady state:}

When $s$ is equal to zero, the economy possesses a steady state in which:

- $\bar{\Delta}=0$ (as in the social planner's problem);

- $\bar{M}=0$ (as in the social planner's problem);

- the unemployment rate satisfies $\delta(N-\bar{U})=2 \bar{\phi}(\bar{U} / 2)^{\sigma}$ (as in the social planner's problem);

- $\bar{\Gamma}_{y}=\frac{f^{\prime}(\bar{L} / 2)-\bar{w}}{\rho+\delta+\phi(\bar{U} / 2)}$ (which is less than $\bar{\gamma}_{y}$ because $\left.\phi(\bar{U} / 2)>\Phi^{\prime}(\bar{U} / 2)\right)$

- $\bar{V}_{u}=\frac{1}{\rho}\left\{\left(\frac{\rho+\delta}{\rho+\delta+\phi(\bar{U} / 2)}\right) \bar{w}+\left(\frac{\phi(\bar{U} / 2)}{\rho+\delta+\phi(\bar{U} / 2)}\right) f^{\prime}(\bar{L} / 2)\right\}$

The finding that $\bar{\Gamma}_{y}>\bar{\gamma}_{y}$ is a reflection of the fact that workers do not fear unemployment enough, as discussed in the text.

C. The response to "shock therapy" reform in a decentralized equilibrium

As above, we linearize (A11) around the steady state described above. The linearization is:

A12.a) $\dot{U}(t)=-k_{1} \hat{U}(t)$

A12.b) $\quad \dot{\Delta}(t)=(\rho+\delta) \hat{\Delta}(t)+\alpha \hat{M}(t)+\bar{w}_{y} \hat{s}(t)$

A12.c) $\dot{M}(t)=\tilde{k}_{2} \hat{\Delta}(t)-\delta \hat{M}(t)$

$$
\dot{\Gamma}_{y}(t)=-k_{3} \hat{U}(t)-k_{4} \hat{\Delta}(t)-(\alpha / 2) \hat{M}(t)+(\rho+\delta+\phi(\bar{U} / 2)) \hat{\Gamma}_{y}(t)-\bar{w}_{y} \hat{s}(t)
$$

where: 


$$
\begin{aligned}
& \tilde{k}_{2}=\frac{\Phi(\bar{U} / 2) \sigma}{(1-\sigma) \bar{\Gamma}_{y}} \\
& \tilde{k}_{3}=(\beta \bar{\Gamma} / \sigma+\alpha) \\
& \tilde{k}_{4}=\Phi^{\prime}(\bar{U} / 2) / \sigma \\
& \tilde{k}_{5}=\left(\rho+\delta+\Phi^{\prime}(\bar{U} / 2) / \sigma\right)
\end{aligned}
$$

and the rest of the parameters are as defined above. The eigenvalues are:

$$
\begin{aligned}
& -\lambda_{1}=-k_{1}<0 \\
& \tilde{\lambda}_{2}=\left(\rho+\sqrt{\rho^{2}+4\left(\delta(\rho+\delta)+\alpha \tilde{k}_{2}\right)}\right) / 2 \\
& -\tilde{\lambda}_{3}=\left(\rho-\sqrt{\rho^{2}+4\left(\delta(\rho+\delta)+\alpha \tilde{k}_{2}\right)}\right) / 2 \\
& \tilde{\lambda}_{4}=\tilde{k}_{5}
\end{aligned}
$$

Noting that with $\sigma>1, \tilde{k}_{2}>k_{2}$ and it follows immediately that the stable root $-\tilde{\lambda}_{3}$ is larger in (absolute value) than the corresponding eigenvalue in the social planner's problem, $-\lambda_{3}$. This justifies the statement, made in the text, that the speed of adjustment to a disturbance will be faster in a decentralized equilibrium than that which would be chosen by a social planner.

Solution of the decentralized equilibrium proceeds as described above, remember that under "shock therapy" $\hat{s}=0$. As before, the gain from employment in sector $\mathrm{Y}$ is:

$$
\Gamma_{y}(0)=\bar{\Gamma}_{y}+\frac{\tilde{Q}_{y}}{\tilde{\lambda}_{4}+\lambda_{1}}+\frac{(\alpha / 2)\left(\tilde{M}+Q_{y}\right)}{\left(\rho+\delta+\tilde{\lambda}_{3}\right)}
$$

where $Q_{y}$ is the number voluntary "quits" or "bankruptcies with which the reform begins. If the the initial shock is large enough (that is, if $\tilde{M}$ is a large enough negative number) these will be positive, and will be large enough to set $\Gamma_{y}(0)=0$. Rearranging (A13) gives a closed form for $Q_{y}$; it is a matter of relatively straightforward algebra to demonstrate that $Q_{y}>q_{y}$, as asserted in the text. 


\section{References}

Aghion, Phillipe and Olivier Blanchard (1993) "On the Speed of Transition in Eastern Europe", manuscript, MIT.

Blanchard, Olivier and Peter Diamond (1990) "The Cyclical Behavior of the Gross Flows of U.S. Workers", Brookings Papers on Economic Activity, 1990:2, 85-155.

Burda, Michael C. (1992) "Unemployment, Labor Market Institutions, and Structural Change in Eastern Europe", manuscript, INSEAD.

Caplin, Andrew and John Leahy (1992) "The Danger of Gradualism in Economic Policy", manuscript, Columbia University.

Davis, Steven J. and John Haltiwanger (1990) "Gross Job Creation and Destruction: Microeconomic Evidence and Macroeconomic Implications", in S. Fischer (ed.) Macroeconomics Annual: 1990, Cambridge: MIT Press.

Dehejia, Vivek (1993) "Sectoral Adjustment and the Political Economy of Gradualism", manuscript, Columbia University.

Diamond, Peter A. (1982) "Wage Determination and Efficiency in Search Equilibrium", Review of Economic Studies, XLIX, 217-227.

Dixit, Avinash and Rafael Rob (1992) "Switching Costs and Sectoral Adjustments in General Equilibrium with Uninsured Risk", manuscript, Princeton University.

Johnson, Harry G. (1965) "Optimal Trade Intervention in the Presence of Factor Distortions", in R.E. Caves et. al. (eds.) Trade, Growth, and the Balance of Payments.

Lapan, Harvey (1976) "Optimal Dynamic Subsidies", American Economic Review.

Meyer, Bruce D, (1990) "Unemployment Insurance and Unemployment Spells", Econometrica, 58:4, 757-782.

Mussa, Michael (1982) "Government Policy and the Adjustment Process", in J. Bhagwati (ed.) Import Competition and Response, Chicago: University of Chicago Press, 73-120.

Neary, J. Peter (1982) "Intersectoral Capital Mobility, Wage Stickiness, and the Case for Adjustment Assistance", in J. Bhagwati (ed.) Import Competition and Response, Chicago: University of Chicago Press.

Rodrik, Dani (1987) "Trade and Capital-Account Liberalization in a Keynesian Economy", Journal of International Economics, 23:1, (August). 